\title{
Clinicopathological and prognostic significance of GPX2 protein expression in esophageal squamous cell carcinoma
}

\author{
Zhijin Lei ${ }^{1}$, Dongping Tian ${ }^{1,2}$, Chong Zhang ${ }^{1}$, Shukun Zhao ${ }^{1}$ and Min Su, ${ }^{1,2^{*}}$ (D)
}

\begin{abstract}
Background: Chaoshan region, a littoral area of Guangdong province in southern China, has a high incidence of esophageal squamous cell carcinoma (ESCC). At present, the prognosis of ESCC is still very poor, therefore, there is urgent need to seek valuable molecular biomarker for prognostic evaluation to guide clinical treatment. GPX2, a selenoprotein, was exclusively expressed in gastrointestinal tract and has an anti-oxidative damage and anti-tumour effect in the progress of tumourigenesis.

Methods: We collected 161 ESCC patients samples, among which 83 patients were followed up. We employed immunochemistry analysis, western blotting and quantitative real-time PCR for measuring the expression of GPX2 within ESCC samples. We analysed the relationship between the expression of GPX2 and clinicopathological parameters of 161 patients with ESCC by Chi-square or Fisher's exact test. The survival analysis of GPX2 expression within ESCC tissues was evaluated by the Kaplan-Meier method and Cox-regression.

Results: A significant higher expression level of GPX2 was detected in tumour tissues compared to that in non-tumour tissues $(P<0.001)$. Moreover, GPX2 expression has statistically significant difference in the tumour histological grade of ESCC $(P<0.001)$, while there was no statistically significant difference in age, sex, tumour size, tumour location, gross morphology and clinical TNM stages $(P>0.05)$. Meanwhile, the expression of GPX2 protein was obviously down-regulated within poorly differentiated ESCC. Last, survival analysis revealed that tumour histological grade and clinical TNM stages, both of the clinical pathological parameters of ESCC, were associated with the prognosis of patients with ESCC (respectively, $P=0.009$, HR (95 \% Cl) $=1.885(1.212 \sim 2.932)$; $P=0.007$, HR $(95 \% \mathrm{Cl})=2.046(1.318 \sim 3.177))$. More importantly, loss expression of GPX2 protein predicted poor prognosis in patients with ESCC $(P<0.001, \mathrm{HR}(95 \% \mathrm{Cl})=5.700(2.337 \sim 13.907))$.
\end{abstract}

Conclusions: Collectively, these results suggested that the expression of GPX2 was significantly up-regulated within ESCC tumour tissues. GPX2 might be an important predictor for the prognosis of ESCC and a potential target for intervention and treatment of ESCC.

Keywords: ESCC, GPX2, Overexpression, Clinicopathological parameters, Prognosis

\footnotetext{
* Correspondence: minsu@stu.edu.cn

'Department of Pathology and Institute of Clinical Pathology, Shantou

University Medical College, Shantou, Guangdong, People's Republic of China

${ }^{2}$ Forensic Identification Center of Shantou University, Shantou University

Medical College, Shantou, Guangdong, People's Republic of China
} 


\section{Background}

Esophageal carcinoma (EC) is one of the most common digestive tract malignancies worldwide, and respectively ranks $8^{\text {th }}$ and $6^{\text {th }}$ in terms of cancer incidence and mortality rate [1]. The Chaoshan area of Guangdong province in China is a high incidence district of EC, where the main histologic type of EC is esophageal squamous cell carcinoma (ESCC). For most patients with EC, the first time going to a doctor is usually started after dysphagia, which means most patients are diagnosed with EC in the mid-late stage of the disease. Unfortunately, the 5-year survival rate of patients with EC ranges from 6 to $50 \%$, but generally less than $30 \%$ [2]. Thus, the early detection of tumour prognostic factors is essential to patients with EC.

Glutathione peroxidase 2 (GPX2), also known as the glutathione peroxidase (GI-GPX), belongs to the antioxidant enzyme glutathione peroxidase family. The antioxidant enzyme family has eight known glutathione peroxidases (GPX1-8) in human [3]. Interestingly, the antioxidant enzyme family obviously exhibits a tissuespecific expression [4]. GPX2 is exclusively expressed in gastrointestinal tract, but in human, GPX2 is also expressed in liver [5], and has been suggested to protect against oxidative damage from food [6]. At present, the overexpression of GPX2 protein is detected in neoplastic transformation of squamous epithelia cells [7], Barrett's esophagus [8], lung cancer [9], breast cancer [10], colorectal cancer $[11,12]$, hepatocellular carcinoma [13] and castration-resistant prostate cancer [14]. Intriguingly, GPX2 may be a candidate as a prognostic marker for castration-resistant prostate cancer [14]. However, the expression of GPX2 within ESCC is rarely reported, and the relationship between GPX2 expression and ESCC prognosis is still unclear. In this study, we found that the expression of GPX2 protein was significantly up-regulated within ESCC tumour tissues compared with non-tumour tissues. More importantly, the expression of GPX2 protein might be correlated with the prognosis of patients with ESCC.

\section{Methods}

\section{Patients and tissue specimen}

In this study, all tissue samples were collected from the Pathology Department of Shantou University Medical College, and their clinical pathological features and diagnosis were verified by two pathologists. Patients who were diagnosed with ESCC and with no radio- or chemo- preoperative therapy were enrolled in this study. We collected samples from 78 patients with ESCC in the year 2012 and separately sampled three sorts of these samples: tumour tissue (inside tumour), tumour-proximal non-malignant tissue (PN, within $2 \mathrm{~cm}$ from tumour) and distant non-malignant tissue
(DN, over $5 \mathrm{~cm}$ away from tumour) (Fig. 1). According to the above standards, there were 60 patients with ESCC who has triple samples, namely tumour tissue, PN tissue and DN tissue. These tissue samples were in duplicate stored in $-80^{\circ} \mathrm{C}$ freezer and embedded by paraffin. We also collected paraffin embedded samples from 83 patients with ESCC in the second half year of 2002 and followed up these patients or their families from July, 2002 to May, 2008. These samples with follow-up were only tumour tissues without PN and DN. On the basis of the 2010 WHO classification of tumours of digestive system [15], ESCC was divided into high differentiated ESCC (ESCCI), moderately differentiated ESCC (ESCCII) and poorly differentiated ESCC (ESCCIII). According to the $7^{\text {th }}$ editions of the Union for International Cancer Control-American Joint Committee on cancer (UICC-AJCC) TNM staging system [16], patients with ESCC was grouped into stages I, II, III and IV. This study was approved by the ethical board of Shantou University Medical College.

\section{Immunohistochemical analysis}

Immunohistochemical staining was performed using the Envision Labelled Peroxidase System (Dako, carpinteria, CA). For immunohistochemical analysis, deparaffinised sections of the tissues were incubated with 1:100 diluted Pierce anti-GPX2 (Rabbit polyclonal antibody, PA5-27150, Thermo Fisher Scientific, Taiwan). The sections were allowed to develop in 3,3-diaminobenzidine (DAB). Negative [PBS instead of primary antibody or isotype-matched non-specific IgG (normal rabbit IgG, A7016, Beyotime, China) (Additional file 1: Figure S1)] and positive (gastric carcinoma) controls were used to confirm the specificity of the primary antibodies. After mounting, sections were scanned by Aperio ePathology AT2 (Leica Biosystems, Germany) and images were captured using a Aperio ImageScope

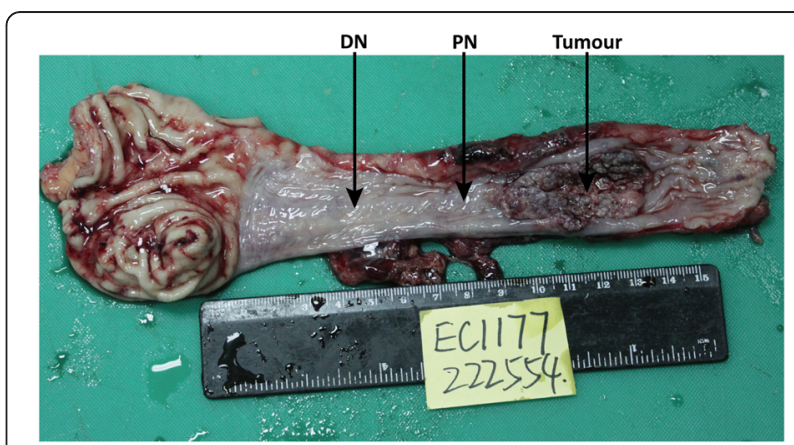

Fig. 1 Schematic illustration of tissue sample collection. Samples without follow-up in this study were collected accordingly: tumour tissue (inside tumour), tumour-proximal non-malignant tissue (PN, within $2 \mathrm{~cm}$ from tumour) and distant non-malignant tissue (DN, over $5 \mathrm{~cm}$ away from tumour) 
(Version 12.1, Leica Biosystems, Germany) at 40x and 200x magnification. The quantitation of GPX2 cytoplasmic immunoreactivity was determinated by the product of the dyeing intensity and the expression rate. The dyeing intensity was divided into four degrees including $0,1,2$ and 3 . When the product was more than 0.5, the expression of GPX2 protein within ESCC tissues was defined as GPX2-positive expression (GPX2+); when less than 0.5, it was defined as GPX2-negative expression (GPX2-).

\section{RNA preparation and quantitative RT-PCR}

The freshly tumour, $\mathrm{PN}$ and DN tissue samples from 7 patients with ESCC were stored in $-80^{\circ} \mathrm{C}$ freezer. After thawing, total RNA was extracted from the freshly tissue samples using an RNeasy MiNi Kit (TianGen, Beijing, China). Reverse transcription was performed using a PrimeScript RT Master Mix Perfect Real Time 100 Reactions Kit (TaKaRa, Dalian, China). For measurement of GPX2 mRNA level, RT-PCR was performed with SYBR Premix EX TaqTM II (TaKaRa, Dalian, China). Primer

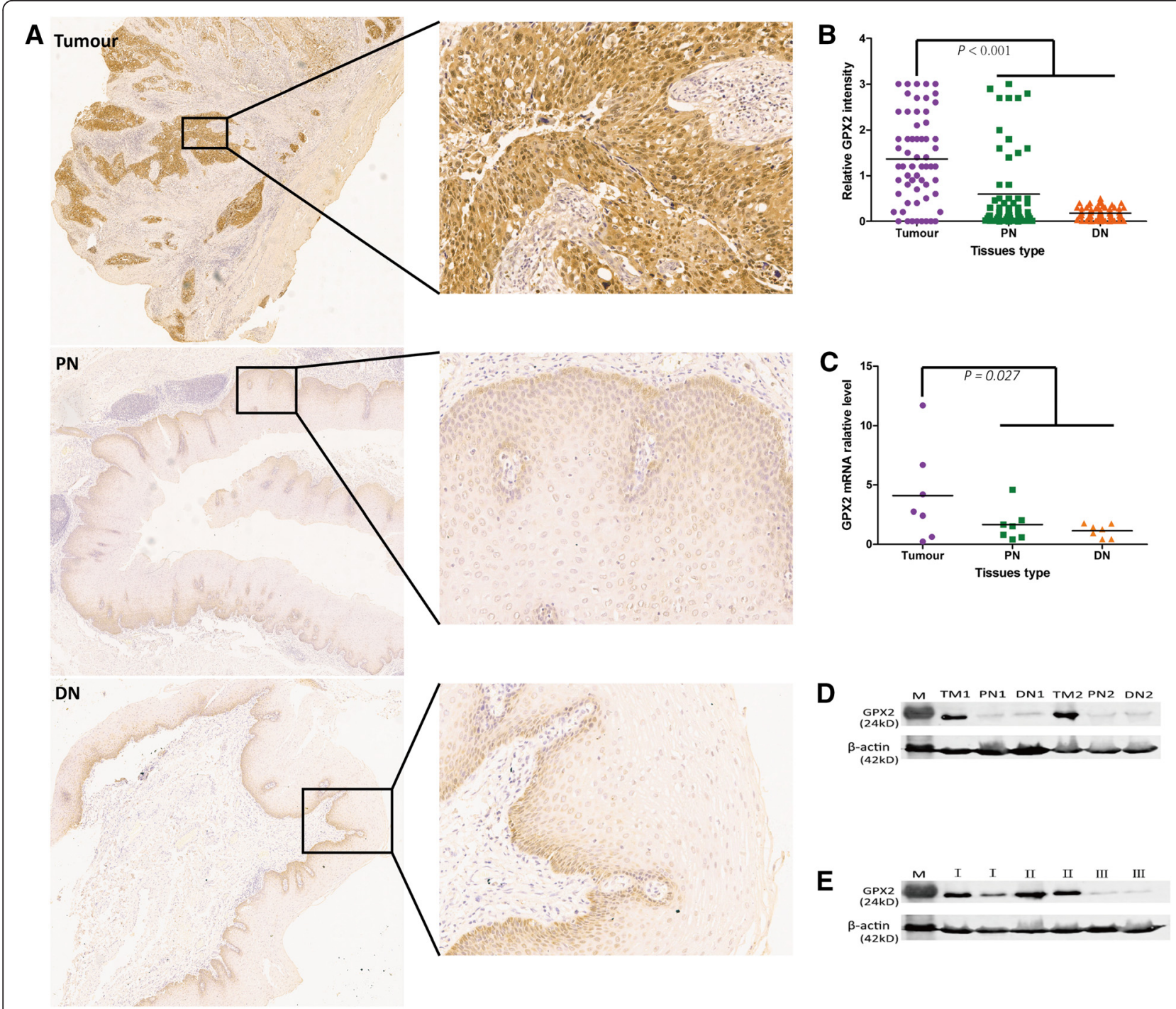

Fig. 2 GPX2 overexpression in tumour tissues compared with non-tumour tissues including PN and DN tissues. a Representative IHC images of GPX2 staining in tumour, PN and DN tissues. $\mathbf{b}$ The immunochemistry analysis of the relative expression of GPX2 in tumour, PN and DN tissues according to staining intensity. There is a statistically significant difference in GPX2 protein expression of tumour tissues compared with compared with non-tumour tissues including PN and DN tissues $(P<0.001)$ studied by the independent-samples test. $\mathbf{c}$ The relative level of GPX2 mRNA expression in tumour, PN and DN tissues. There is statistically significant difference in GPX2 mRNA expression of tumour tissues compared with compared with non-tumour tissues including PN and DN tissues $(P=0.027)$ studied by the independent-samples test. $\mathbf{d}$ Western blot analysis of GPX2 protein in tumour, PN and DN tissues from two patients within ESCC. Obviously, GPX2 protein was overexpressed in tumor tissues compared with PN and DN tissues. e Western blot analysis of GPX2 protein in ESCCI, ESCCII and ESCCIII tissues from six patients with ESCC. Obviously, the expression of GPX2 protein was down-regulated in ESCCIII tissues compared with ESCCI and ESCCII tissues. M: protein marker; TM: tumour;:!: ESCCl; II: ESCCII; III: ESCCIII 
sequences were 5' - TGCAACCAATTTGGACATCAG - 3' and 5'- AGACAGGATGCTCGTTCTGC-3' for human GPX2; 5'-CAGCCTCAAGATCATCAGCA - 3' and 5' ATGATGTTCTGGAGAGCCCC - 3' for human glyceraldehyde-3-phosphate dehydrogenase (GAPDH). The following experiments were performed in triplicate in a 7300 Real-Time PCR System (ABI, USA). Analysis of relative GPX2 gene expression data was using real-time quantitative PCR and the the $2^{-\Delta \Delta C T}$ Method [17].

\section{Western blotting analysis}

The freshly tumour, PN and DN tissue samples from 6 patients with ESCC and freshly tumour tissue samples from other 6 patients with ESCC were lysed in RIPA buffer in the presence of $1 \times$ protease inhibitor cocktail (Sigma-Aldrich, USA). $50 \mu \mathrm{g}$ of total protein was resolved on $10 \%$ sodium dodecyl sulfate-polyacrylamide gels and transferred onto PVDF membranes $(0.45 \mu \mathrm{m}$, Amersham Pharmacia, USA). The expression level of GPX2 was assessed by Pierce anti-GPX2 (Rabbit polyclonal antibody, $24 \mathrm{kDa}, 1: 1000$, PA5-27150, Thermo Fisher Scientific, Taiwan). Beta actin ( $\beta$-actin) expression was evaluated to confirm equal amounts of protein loading using a mouse monoclonal anti-beta-actin antibody (42 kDa, 1:10000, Mab1445, Sigma-Aldrich, USA). After incubated with Goat anti-rabbit or mouse antibody (1:10000, 680RD, LI-COR biosciences, Germany), identification of the bands was scanned by Odyssey infrared imaging system (LI-COR biosciences, Germany). The outcome images were exported by Odyssey application software (Version 3.0, LI-COR biosciences, Germany).

\section{Statistical analysis}

All data was analysed with SPSS statistics software (Version 19.0, Chicago, IL, USA). Relationships between GPX2 expression and ESCC clinicopathological features were studied using the Chi-square test or Fisher's exact test. The GPX2 expression of tumor tissues compared with that of non-tumour tissues including PN and DN tissues was studied by the independent-samples test. Survival time was calculated from the date of surgery to the date of death or the last follow-up time. The correlation of different survival time with ESSC characteristics, clinical features and GPX2 were evaluated by using the Kaplan-Meier method. The log-rank test was used to analyse survival differences. The hazard ratio (HR) and $95 \%$ confidence interval $(\mathrm{CI})$ were calculated by univariate or multivariate Cox regression analysis. In order to identify the predictors of ESCC outcome, we used Cox stepwise regression for calculation with a significance level of $P<0.05$ for entering and $P>0.10$ for removing the respective explanatory variables. A $P$ value of less than 0.05 was considered as statistically significant difference.

\section{Results}

GPX2 protein was overexpressed within ESCC tumour tissues As detected in other tumours, the expression of GPX2 protein was markedly up-regulated within ESCC tumour tissues. In this study, immunohistochemistry (IHC) results of triple samples of 60 patients with ESCC showed that the significant higher expression level of GPX2 protein was detected in ESCC tumour tissues compared with nontumour including $\mathrm{PN}$ and $\mathrm{DN}$ tissues $(P<0.001)$ (Fig. 2a and $b)$. To further verify the IHC results of the expression of GPX2 protein, western blotting and RT-PCR were employed by this study. Under equal-weight protein samples, western blotting results showed that GPX2 was obviously overexpressed within ESCC tumour tissues compared with non-tumour including PN and DN (Fig. 2d and Additional file 2: Figure S2). The interesting

Table 1 The relationship between GPX2 protein expression and ESCC patients' clinicopathological characteristics

\begin{tabular}{|c|c|c|c|c|}
\hline Clinical features & Cases & GPX2+ & GPX2- & $P$ value \\
\hline \multicolumn{5}{|l|}{ Age } \\
\hline$\leq 58$ years & 83 & 70 & 13 & \multirow[t]{2}{*}{0.539} \\
\hline$>58$ years & 78 & 62 & 16 & \\
\hline \multicolumn{5}{|l|}{ Sex } \\
\hline Male & 117 & 95 & 22 & \multirow[t]{2}{*}{0.670} \\
\hline Female & 44 & 37 & 7 & \\
\hline \multicolumn{5}{|l|}{ Size } \\
\hline$\leq 4.5 \mathrm{~cm}$ & 98 & 83 & 15 & \multirow[t]{2}{*}{0.265} \\
\hline$>4.5 \mathrm{~cm}$ & 63 & 49 & 14 & \\
\hline \multicolumn{5}{|l|}{ Site } \\
\hline Upper & 13 & 12 & 1 & \multirow[t]{3}{*}{0.380} \\
\hline Middle & 107 & 89 & 18 & \\
\hline Below & 41 & 31 & 10 & \\
\hline \multicolumn{5}{|c|}{ Gross morphology } \\
\hline Medullary & 79 & 69 & 10 & \multirow[t]{4}{*}{0.258} \\
\hline Umbrella & 11 & 9 & 2 & \\
\hline Ulcer & 54 & 40 & 14 & \\
\hline Stenosis & 17 & 14 & 3 & \\
\hline \multicolumn{5}{|c|}{ Histological grade } \\
\hline I & 46 & 41 & 5 & \multirow[t]{3}{*}{$<0.001$} \\
\hline$\|$ & 94 & 86 & 8 & \\
\hline III & 21 & 5 & 16 & \\
\hline \multicolumn{5}{|l|}{ TNM stages } \\
\hline $\mid \sim \|$ & 86 & 75 & 11 & \multirow[t]{3}{*}{0.118} \\
\hline III & 73 & 55 & 18 & \\
\hline IV & 2 & 2 & 0 & \\
\hline
\end{tabular}

GPX2+: ESCC with GPX2-positive expression; GPX2-: ESCC with GPX2-negative expression

Histological grade: I, high differentiated ESCC; II, moderately differentiated ESCC; III, poorly differentiated ESCC 
phenomenon was also simultaneously demonstrated by the RT-PCR result of GPX2 mRNA $(P=0.027)$ (Fig. 2c). Hence the expression of GPX2 protein was significantly upregulated within ESCC tumour tissues.

\section{Expression of GPX2 protein significantly correlated with tumour histological grade of ESCC}

According to the IHC results of GPX2 protein expression within ESCC tumour tissues, we divided ESCC patients into two groups, namely GPX2-positive expression (GPX2+) group and GPX2-negative expression (GPX2-) group. We found that GPX2 protein was expressed positively in $82.0 \%$ (132 out of 161) of the cases of ESCC. Further, we analysed the relationship between the expression of GPX2 protein and ESCC patients' clinicopathological characteristics. We found that the expression of GPX2 protein has statistically significant difference in the tumour histological grade of ESCC $(P<0.001)$, while there were no statistically significant difference in age, sex, tumour size, tumour location, gross morphology and clinical TNM stages $(P>0.05)$ (Table 1). Therefore, the expression of GPX2 protein was significantly related to the tumour histological grade of ESCC. Furthermore, we detected another important phenomenon that GPX2 protein was hardly expressed within ESCCIII compared with ESCCIand ESCCII (Fig. 2e).

Negatively-expression of GPX2 protein predicted a poorer prognosis in ESCC patients

In the prognostic analysis of 83 ESCC patients with follow-up, firstly, survival analysis of the clinical

Table 2 Survival analysis of the clinical pathological parameters

\begin{tabular}{|c|c|c|c|c|c|}
\hline Clinical features & Cases & Mortality & MST (95 \% Cl) & Log-rank $P$ value & $\mathrm{HR}(95 \% \mathrm{Cl})$ \\
\hline \multicolumn{6}{|l|}{ Age } \\
\hline$\leq 58$ years & 45 & 35 & $26(16.141 \sim 38.859)$ & \multirow[t]{2}{*}{0.850} & \multirow[t]{2}{*}{$1.049(0.637 \sim 1.725)$} \\
\hline$>58$ years & 38 & 28 & $18(5.918 \sim 30.082)$ & & \\
\hline \multicolumn{6}{|l|}{ Sex } \\
\hline Male & 60 & 46 & $26(13.348 \sim 38.652)$ & \multirow[t]{2}{*}{0.796} & \multirow[t]{2}{*}{$1.075(0.616 \sim 1.876)$} \\
\hline Female & 23 & 17 & $18(8.609 \sim 27.391)$ & & \\
\hline \multicolumn{6}{|l|}{ Size } \\
\hline$\leq 4.5 \mathrm{~cm}$ & 48 & 35 & $29(17.118 \sim 40.882)$ & \multirow[t]{2}{*}{0.339} & \multirow[t]{2}{*}{$1.270(0.772 \sim 2.088)$} \\
\hline$>4.5 \mathrm{~cm}$ & 35 & 28 & $19(4.512 \sim 33.488)$ & & \\
\hline \multicolumn{6}{|l|}{ Site } \\
\hline Upper & 9 & 6 & 33 (0 73.905) & \multirow[t]{3}{*}{0.028} & \multirow[t]{3}{*}{$1.803(0.992 \sim 3.278)$} \\
\hline Middle & 65 & 48 & 29 (18.467 39.533) & & \\
\hline Below & 9 & 9 & $11(5.156 \sim 16.844)$ & & \\
\hline \multicolumn{6}{|c|}{ Gross morphology } \\
\hline Medullary & 62 & 46 & $30(9.755 \sim 50.245)$ & \multirow[t]{4}{*}{$<0.001$} & \multirow[t]{4}{*}{$1.252(0.942 \sim 1.663)$} \\
\hline Umbrella & 5 & 4 & 9 (6.853 11.147) & & \\
\hline Ulcer & 13 & 10 & $20(10.605 \sim 29.395)$ & & \\
\hline Stenosis & 3 & 3 & $6(4.400 \sim 7.600)$ & & \\
\hline \multicolumn{6}{|c|}{ Histological grade } \\
\hline 1 & 32 & 20 & $47(10.966 \sim 83.034)$ & \multirow[t]{3}{*}{0.009} & \multirow[t]{3}{*}{$1.885(1.212 \sim 2.932)$} \\
\hline$\|$ & 46 & 38 & $20(8.616 \sim 31.384)$ & & \\
\hline III & 5 & 5 & $8(5.853 \sim 10.147)$ & & \\
\hline \multicolumn{6}{|l|}{ TNM stages } \\
\hline$|\sim| \mid$ & 49 & 32 & $42(22.796 \sim 61.204)$ & \multirow[t]{3}{*}{0.007} & \multirow[t]{3}{*}{$2.046(1.318 \sim 3.177)$} \\
\hline III & 32 & 29 & $14(6.608 \sim 21.392)$ & & \\
\hline IV & 2 & 2 & - & & \\
\hline \multicolumn{6}{|l|}{ Treatment } \\
\hline No & 41 & 31 & $19(3.944 \sim 34.056)$ & \multirow[t]{2}{*}{0.529} & \multirow[t]{2}{*}{$0.855(0.522 \sim 1.402)$} \\
\hline Yes & 42 & 32 & $22(10.886 \sim 33.114)$ & & \\
\hline
\end{tabular}


pathological parameters showed that both tumour histological grade and clinical TNM stages were notably related to the prognosis of patients with ESCC (respectively, $P=0.009$, HR $(95 \% \mathrm{CI})=1.885(1.212 \sim$ 2.932); $P=0.007$, HR (95 \% CI $)=2.046 \quad(1.318 \sim$ 3.177)), while there were no statistically significant differences in age, sex, tumour size, tumour location, gross morphology and radiotherapy or chemotherapy after surgery $(P>0.05$ or the lower limit of HR $(95 \%$ $C I)<1)$ (Table 2). Secondly, we carried on the prognostic analysis of the expression of GPX2 protein in 83 ESCC patients with follow-up. Those with negative-expression GPX2 in their biopsy specimen had significantly poorer prognosis than those with positive-expression GPX2 $(P<0.001) \quad$ (Table 3 and Fig. 3). One-year survival rates of both positiveexpression group and negative-expression group of GPX2 protein were $71.1 \%$ and 0 , and median survival time (MST) were $29(15.117 \sim 42.883)$ and 8 (5.434 10.566), respectively (Table 3 ). In the Cox regression model analysis, we found that the expression of GPX2 protein $(P<0.001$, HR $(95 \% \mathrm{CI})=5.700 \quad(2.337 \sim$ 13.907) $)$ and tumour histological grade $(P=0.01$, HR $(95 \%$ CI $)=1.739(1.143 \sim 2.646))$ influenced on the long-term survival of ESCC patients, and were death risk factors of ESCC patients (Table 4). Adjusting for the other factor, the death risk of GPX2-negative expression was 4.7 times more than GPX2-positive expression. Thus negatively-expression of GPX2 protein predicted significantly a poorer prognosis in patients with ESCC.

\section{Discussion}

EC is an aggressive malignant neoplasm with a poor prognosis. The 5-year survival rates of patients with EC ranges from 15 to $24 \%$ [18]. In China, EC ranks $5^{\text {th }}$ in the most common cancer and $4^{\text {th }}$ in the leading cause of cancer death [19]. The two major histological subtypes of EC is ESCC and esophageal adenocarcinomas (EAC). In contrast to EAC, ESCC has a high prevalence in Asia and South Africa [20]. The consumption of hot food and beverages is considered as an increased risk of esophageal cancer, particularly ESCC [21]. The traditional treatment, like surgery, radiotherapy and chemotherapy, do not bring

Table 3 Survival analysis of 83 patients between GPX2 + and GPX2 -

\begin{tabular}{lllllll}
\hline GPX2 & Cases & Death & MST $(95 \% \mathrm{Cl})$ & $\begin{array}{l}\text { One-year } \\
\text { survival } \\
\text { rate }(\%)\end{array}$ & & ( value \\
\hline+ & 76 & 56 & $29(15.117 \sim 42.883)$ & 71.1 & 22.587 & $<0.001$ \\
$P$ value & \\
- & 7 & 7 & $8(5.434 \sim 10.566)$ & 0 & & \\
\hline
\end{tabular}

GPX2+: ESCC with GPX2-positive expression; GPX2-: ESCC with GPX2-negative expression

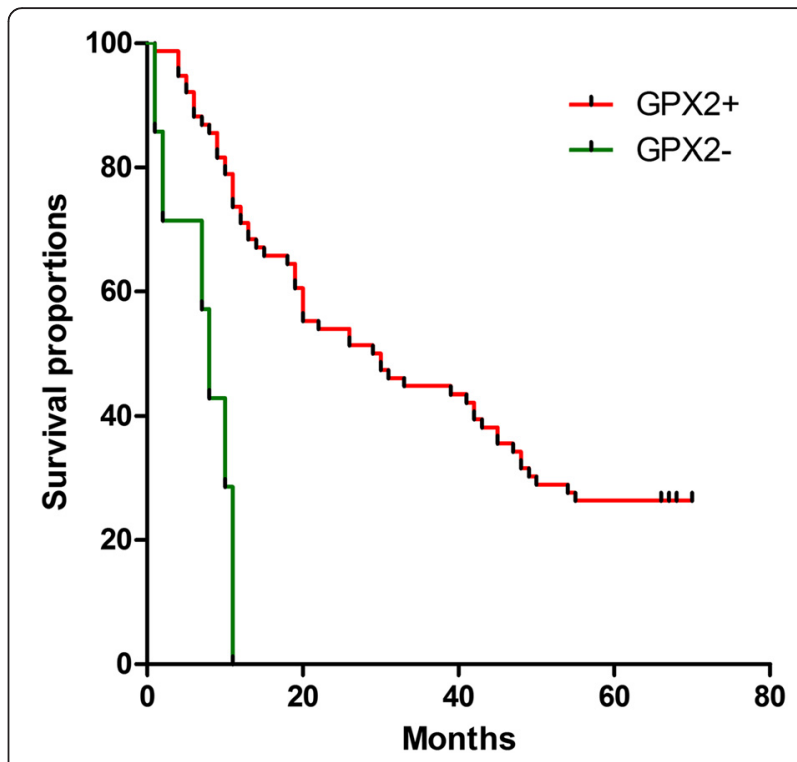

Fig. 3 Prognostic analysis of 83 patients with ESCC according to presence of and absence of GPX2 expression. GPX2 positive patients: $n=76$, GPX2 negative patients: $n=7, P<0.001$

a greater benefits to patients with EC. Even worse, there is no a better prognostic factor which can predict the life expectancy of patients with EC. Therefore, the prognostic factor of EC should deserve to make it.

Glutathione peroxidases (GPXs) is a family of antioxidant enzymes. The biochemical function of GPXs is to reduce $\mathrm{H}_{2} \mathrm{O}_{2}$ or organic hydroperoxides to water or their corresponding alcohols respectively [22]. At the present, the GPX family consists of eight members: GPX1, GPX2, GPX3, GPX4, GPX5, GPX6, GPX7 and GPX8 [4]. In particular, GPX2, also a selenium-dependent enzyme, is specifically expressed within the gastrointestinal tract in human being [5]. Therefore, GPX2 can be considered as one of the most important defence systems against oxidative damage from the consumption of hot food and beverages. Impressively, GPX2 has an anti-inflammatory and anti-tumour effect in the course of the tumorigenesis [23]. Compared with normal tissues, cancer cells produce a higher level of reactive oxygen species (ROS) [24] and cancer tissues suffer from a severer oxidative damage $[25,26]$. As expected, the expression of GPX2 protein is up-regulated within various cancer tissues.

Based on epidemiological study, the reproducibility of a semi-quantitative food frequency questionnaire showed the daily intake of selenium was $81.8 \sim 231.2 \mu \mathrm{g}$ in the diets

Table 4 Cox regression of 83 patients with ESCC

\begin{tabular}{lllllll}
\hline Variable & $\mathrm{B}$ & $\mathrm{SE}(\mathrm{B})$ & Wald $X^{2}$ & $P$ value & $\mathrm{HR}$ & $\mathrm{HR} 95 \% \mathrm{Cl}$ \\
\hline GPX2 & 1.741 & 0.455 & 14.630 & $<0.001$ & 5.700 & $2.337 \sim 13.907$ \\
Histological grade & 0.553 & 0.214 & 6.688 & 0.010 & 1.739 & $1.143 \sim 2.646$ \\
\hline
\end{tabular}


of Chaoshan inhabitants [27], and in our previous study, the hair selenium level of Chaoshan inhabitants was about $0.48 \mathrm{mg} / \mathrm{L}$ [28]. According to the 50 250 $\mu$ g of suitable range of the daily selenium intake of Chinese residents [29], the selenium supply of inhabitants in Chaoshan region is appropriate. Convincingly, GPX2 protein was significantly overexpressed within ESCC tumour tissues compared with non-tumour tissues in this study. GPX2 may play an important role in anti-tumour within ESCC tumour tissues, while ESCC with a loss expression of GPX2 protein is prone to progress to the poor differentiated ESCC. Because of the limited samples with follow-up, whether or not GPX2 is expected to be a monitoring prognostic factor of patients with ESCC, it is still open for further experimentation.

\section{Conclusions}

To sum up, the expression of GPX2 protein was significantly up-regulated within ESCC tumour tissues compared with non-tumour tissues. GPX2 might be an important predictor for the prognosis of patients with ESCC.

\section{Additional files}

Additional file 1: Figure S1. Representative $\mathrm{IHC}$ images of normal rabbit IgG as negative control. Images were captured using a Leica IM50 microscope (Imagic Bildverarbeitung AG, Wetzlar, Germany) at 40× (A) and $200 \times$ (B) magnification. (TIF $4013 \mathrm{~kb}$ )

Additional file 2: Figure S2. Western blot analysis of GPX2 protein in tumour, PN and DN tissues from other 4 patients with ESCC. Obviously, GPX2 protein was overexpressed in tumor tissues compared with PN and DN tissues. M: protein marker; TM: tumour;: ESCCl; II: ESCCII; III: ESCCIII. (TIF $1324 \mathrm{~kb}$ )

\section{Abbreviations}

ESCC, esophageal squamous cell carcinoma; GPX2, glutathione peroxidase 2

\section{Acknowledgements}

We are sincerely grateful to Runhua Lin for critically reading the manuscript.

\section{Funding}

This study was sponsored by NSFC-Guangdong Joint Fund Key Project (Certificates U1132004) and NSFC (Certificates 31171226).

\section{Availability of data and materials}

The dataset supporting the conclusions of this article is included within the article and its Supplementary material Figure S1 and Figure S2. The dataset will be shared upon request.

\section{Authors' contributions}

MS and DPT conceived and supervised the study. ZJL performed the experiments, did all of the data analysis and wrote the manuscript with help from all of authors. CZ participated in some of the experiments. SKZ participated in some of writing the manuscript. All authors approved the final manuscript.

\section{Authors' information}

All authors come from the Department of Pathology and Institute of Clinical Pathology. ZJL is a Ph.D. student. DPT is a pathologist and a professor. CZ is a Ph.D. student. SKZ is a technician. MS is a pathologist and a professor, and a director of the Department of Pathology and Institute of Clinical Pathology and the Forensic Identification center of Shantou University.

\section{Competing interests}

All authors declare that they have no competing interests.

\section{Consent for publication}

Not applicable.

\section{Ethics approval and consent to participate}

This study was approved by the ethical board of Shantou University Medical College before the experimental protocol was employed, verbal informed consent was obtained from patients and their families.

Received: 21 January 2016 Accepted: 27 June 2016

Published online: 07 July 2016

\section{References}

1. Jemal A, Bray F, Center MM, Ferlay J, Ward E, Forman D. Global cancer statistics. CA Cancer J Clin. 2011;61(2):69-90.

2. Peppelenbosch MP, Spaander MC, Bruno MJ. Glutathione peroxidase 7 prevents cancer in the oesophagus. Gut. 2014;63(4):537-8.

3. Toppo S, Vanin S, Bosello V, Tosatto SC. Evolutionary and structural insights into the multifaceted glutathione peroxidase (Gpx) superfamily. Antioxid Redox Signal. 2008;10(9):1501-14.

4. Brigelius-Flohe R, Maiorino M. Glutathione peroxidases. Biochim Biophys Acta. 2013;1830(5):3289-303.

5. Chu FF, Doroshow JH, Esworthy RS. Expression, characterization, and tissue distribution of a new cellular selenium-dependent glutathione peroxidase, GSHPx-Gl. J Biol Chem. 1993;268(4):2571-6.

6. Brigelius-Flohe R. Tissue-specific functions of individual glutathione peroxidases. Free Radic Biol Med. 1999;27(9-10):951-65.

7. Serewko MM, Popa C, Dahler AL, Smith L, Strutton GM, Coman W, Dicker AJ, Saunders NA. Alterations in gene expression and activity during squamous cell carcinoma development. Cancer Res. 2002;62(13):3759-65.

8. Mork H, Scheurlen M, Al-Taie O, Zierer A, Kraus M, Schottker K, Jakob F, Kohrle J. Glutathione peroxidase isoforms as part of the local antioxidative defense system in normal and Barrett's esophagus. Int J Cancer. 2003; 105(3):300-4.

9. Woenckhaus M, Klein-Hitpass L, Grepmeier U, Merk J, Pfeifer M, Wild P, Bettstetter M, Wuensch P, Blaszyk H, Hartmann A, et al. Smoking and cancer-related gene expression in bronchial epithelium and non-small-cell lung cancers. J Pathol. 2006;210(2):192-204.

10. Naiki-lto A, Asamoto M, Hokaiwado N, Takahashi S, Yamashita H, Tsuda H, Ogawa K, Shirai T. Gpx2 is an overexpressed gene in rat breast cancers induced by three different chemical carcinogens. Cancer Res. 2007;67(23):11353-8.

11. Chiu ST, Hsieh FJ, Chen SW, Chen CL, Shu HF, Li H. Clinicopathologic correlation of up-regulated genes identified using cDNA microarray and real-time reverse transcription-PCR in human colorectal cancer. Cancer Epidemiol Biomarkers Prev. 2005;14(2):437-43.

12. Murawaki Y, Tsuchiya H, Kanbe T, Harada K, Yashima K, Nozaka K, Tanida O, Kohno M, Mukoyama T, Nishimuki E, et al. Aberrant expression of selenoproteins in the progression of colorectal cancer. Cancer Lett. 2008; 259(2):218-30.

13. Suzuki S, Pitchakarn P, Ogawa K, Naiki-Ito A, Chewonarin T, Punfa W, Asamoto M, Shirai T, Takahashi S. Expression of glutathione peroxidase 2 is associated with not only early hepatocarcinogenesis but also late stage metastasis. Toxicology. 2013;311(3):115-23.

14. Naiki T, Naiki-Ito A, Asamoto M, Kawai N, Tozawa K, Etani T, Sato S, Suzuki S, Shirai T, Kohri K, et al. GPX2 overexpression is involved in cell proliferation and prognosis of castration-resistant prostate cancer. Carcinogenesis. 2014;35(9):1962-7.

15. Li ZS, Li Q. The latest 2010 WHO classification of tumors of digestive system. Zhonghua Bing Li Xue Za Zhi. 2011:40(5):351-4.

16. Rice TW, Blackstone EH, Rusch WW. 7th edition of the AJCC Cancer Staging Manual: esophagus and esophagogastric junction. Ann Surg Oncol. 2010;17(7):1721-4

17. Livak KJ, Schmittgen TD. Analysis of relative gene expression data using real-time quantitative PCR and the 2(-Delta Delta C(T)) Method. Methods. 2001;25(4):402-8.

18. Enzinger PC, Mayer RJ. Esophageal cancer. N Engl J Med. 2003;349(23):2241-52.

19. Chen W, Zheng R, Zhang S, Zhao P, Zeng H, Zou X. Report of cancer incidence and mortality in China, 2010. Ann Transl Med. 2014;2(7):61. 
20. Kamangar F, Dores GM, Anderson WF. Patterns of cancer incidence, mortality, and prevalence across five continents: defining priorities to reduce cancer disparities in different geographic regions of the world. J Clin Oncol. 2006;24(14):2137-50.

21. Andrici J, Eslick GD. Hot food and beverage consumption and the risk of esophageal cancer: a meta-analysis. Am J Prev Med. 2015;49(6):952-60.

22. Ursini F, Maiorino M, Brigelius-Flohe R, Aumann KD, Roveri A, Schomburg D, Flohe L. Diversity of glutathione peroxidases. Methods Enzymol. 1995;252:38-53.

23. Brigelius-Flohe R, Kipp AP. Physiological functions of GPx2 and its role in inflammation-triggered carcinogenesis. Ann N Y Acad Sci. 2012;1259:19-25.

24. Brigelius-Flohe R, Kipp A. Glutathione peroxidases in different stages of carcinogenesis. Biochim Biophys Acta. 2009;1790(11):1555-68.

25. Raza Y, Khan A, Farooqui A, Mubarak M, Facista A, Akhtar SS, Khan S, Kazi IJ, Bernstein C, Kazmi SU. Oxidative DNA damage as a potential early biomarker of Helicobacter pylori associated carcinogenesis. Pathol Oncol Res. 2014;20(4):839-46

26. Farinati $F$, Cardin R, Degan $P$, Rugge $M$, Mario FD, Bonvicini $P$, Naccarato $R$. Oxidative DNA damage accumulation in gastric carcinogenesis. Gut. 1998; 42(3):351-6.

27. Li K, Takezaki T, Lv LW, Yu P, Song FY, Tajima K. Reproducibility of a semi-quantitative food frequency questionnaire in Chaoshan area, China. Asian Pac J Cancer Prev. 2005;6(4):521-6.

28. Su M, Liu M, Tian DP, Li XY, Yang HL, Huang HH, et al. Epidemiological investigating of the morbidity rate of malignant tumors and their diet habitats among residents of Nanao island in South China sea. J Environ Occup Med. 2005;22(4):312-6.

29. Guangqi Y. Studies on human requirement of selenium. Chin J Endemiol. 1989;8(5):298-302.

\section{Submit your next manuscript to BioMed Central and we will help you at every step:}

- We accept pre-submission inquiries

- Our selector tool helps you to find the most relevant journal

- We provide round the clock customer support

- Convenient online submission

- Thorough peer review

- Inclusion in PubMed and all major indexing services

- Maximum visibility for your research

Submit your manuscript at www.biomedcentral.com/submit 